\title{
Hypothalamic expression of ART, a novel gene related to agouti, is up-regulated in obese and diabetic mutant mice
}

\author{
John R. Shutter, Melissa Graham, Amy C. Kinsey, Sheila Scully, Roland Lüthy, and Kevin L. Stark ${ }^{1}$ \\ Amgen Inc., Amgen Center, Thousand Oaks, California 91320 USA
}

We have isolated cDNA clones that encode a novel human gene related to agouti. Sequence analysis of this gene, named ART, for agouti-related transcript, predicts a 132-amino-acid protein that is $25 \%$ identical to human agouti. The highest degree of identity is within the carboxyl terminus of both proteins. Like agouti, ART contains a putative signal sequence and a cysteine rich carboxyl terminus, but lacks the region of basic residues and polyproline residues found in the middle of the agouti protein. Both agouti and ART contain 11 cysteines, and 9 of these are conserved spatially. ART is expressed primarily in the adrenal gland, subthalamic nucleus, and hypothalamus, with a lower level of expression occurring in testis, lung, and kidney. The murine homolog of ART was also isolated and is predicted to encode a 131-amino-acid protein that shares $81 \%$ amino acid identity to humans. The mouse was found to have the same expression pattern as human when assessed by RT-PCR. Examination by in situ hybridization using mouse tissues showed localized expression in the arcuate nucleus of the hypothalamus, the median eminence, and the adrenal medulla. In addition, the hypothalamic expression of ART was elevated $\sim 10$-fold in $o b / o b$ and $d b / d b$ mice. ART was mapped to human chromosome 16q22 and to mouse chromosome 8D1-D2. The expression pattern and transcriptional regulation of ART, coupled with the known actions of agouti, suggests a role for ART in the regulation of melanocortin receptors within the hypothalamus and adrenal gland, and implicates this novel gene in the central control of feeding.

[Key Words: Agouti; obesity; melanocortin receptors]

Received January 2, 1997; revised version accepted January 30, 1997.

A previously uncharacterized expressed sequence tag (EST) has been identified by homology to agouti, and named ART for agouti-related transcript. The sequence conservation between ART and agouti suggests that these genes may play similar roles in cellular signaling. Mouse agouti $(\mathrm{A})$ is relatively well characterized, and is most commonly associated with the regulation of coat pigmentation (Searle 1968). Early phenotypic comparison of mouse mutants at the agouti and extension loci suggested that the agouti gene product acts as an antagonist to the extension gene product (Takeuchi et al. 1989). Subsequent cloning and biochemistry has confirmed this prediction. The extension gene encodes the melanocortin-1 receptor (MCl-R) that, when occupied by melanocyte-stimulating hormone ( $\alpha$-MSH), causes the melanocyte to synthesize black pigment (for review, see Jackson 1993). The mouse agouti gene encodes a secreted 131amino-acid protein (Bultman et al. 1992) that acts as an antagonist at this receptor, blocking the action of

${ }^{1}$ Corresponding author.

E-MAIL kstark@amgen.com; FAX (805) 499-9931.
$\alpha-\mathrm{MSH}$, and resulting in hairs with yellow pigment (Lu et al. 1994).

Much of the interest in agouti, however, is related to other dominant phenotypes that result from ectopic expression in mutant mice $\left(\mathrm{A}^{\mathrm{y}}\right)$, such as obesity, hyperinsulinemia, diabetes, and increased tumor susceptibility (for review, see Manne et al. 1995). These pleiotrophic effects suggest that agouti may be exerting its dominant phenotype in the mouse by interacting with other melanocortin receptor family members. There are currently five known receptors; two of these, MC1-R and MC2-R, show relative specificity for the ligands $\alpha-\mathrm{MSH}$ and adrenocorticotrophic hormone (ACTH), respectively (Mountjoy et al. 1992). Of the other three receptors, MC3- $\mathrm{R}$ is expressed in specific brain regions, whereas MC4-R is expressed more widely throughout the brain and spinal cord, and MC5-R is expressed in numerous peripheral tissues (Mountjoy et al. 1992, 1994; RoselliRehfuss et al. 1993; Labbe et al. 1994). Because adrenalectomized, agouti-expressing animals still develop obesity, the MC2-R is not implicated in the etiology of this phenotype (Cone et al. 1996). Partially purified mouse 
agouti is a potent antagonist of the MC1-R and MC4-R, but not MC3-R or MC5-R (Lu et al. 1994).

Recent data have implicated MC4-R as important in the control of feeding and in the pathogenesis of obesity caused by agouti. Mice in which the MC4-R gene was deleted show an obese phenotype that mimicks that of the mutant $\mathrm{A}^{\mathrm{y}}$ mouse (Huszar et al. 1997). In addition, agonists of MC3-R and MC4-R have inhibited feeding, whereas antagonists of these receptors have increased feeding (Fan et al. 1997).

Elevated levels of agouti are also associated with increased intracellular calcium in skeletal muscle (Zemel et al. 1995). Although no direct action of agouti on calcium channels has been reported, an intriguing peptide homology exists with ion channel blockers from spider and snail toxins (Ichida et al. 1993; Figueiredo et al. 1995). This homology is mainly confined to the spacing of eight cysteines in the carboxyl terminus. A carboxyterminal fragment of agouti, which retains these cysteines, is also a potent antagonist of $\alpha-\mathrm{MSH}$ at the MCl-R (Willard et al. 1995), which further implicates this region as an important determinant of biological activity.

Human agouti is expressed in skin, heart, testes, ovary, and adipose tissue. The discordant expression pattern between mouse and humans suggests that agouti is regulating different functions in these species (Kwon et al. 1994; Wilson et al. 1995). Although the role of agouti in humans is not known, its dominant effects on obesity and diabetes observed in the mouse, its activity at melanocortin receptors, and its influence on calcium levels suggest a role for this, and related proteins, in regulating critical signaling pathways.

The molecular cloning and characterization of ART, the first gene identified that shows homology to agouti, establishes the presence of a new gene family. The sequence conservation between ART and agouti, its expression pattern in humans and mice, and the up-regulation of ART expression in animal models of obesity all implicate this novel gene in the regulation of signaling through melanocortin receptors or intracellular calcium levels, or both.

\section{Results}

\section{GenBank search}

The public EST database was searched with a sequence profile constructed from the human and murine agouti peptide sequences. One submission laccession no. H63735) was found to have homology to this profile, consisting of $\sim 160 \mathrm{bp}$ at the $3^{\prime}$ end of the genes. The submitted sequence contained seven cysteines that aligned with agouti but also contained an in-frame termination codon amino terminal to this region. The submission containing the sequence from the opposite end of this clone (accession no. H63298) did not show any homology to the profile.

The bacterial stock containing the cDNA clone (accession no. 208641) corresponding to these two sequence sub- missions was obtained and found to contain an insert of $\sim 1.5 \mathrm{~kb}$. Analysis of the full insert sequence confirmed the presence of the agouti homology in the cysteine-rich carboxyl terminus. The in-frame stop codon reported in H63735 was resolved as a frame-shift sequencing error in the EST sequence; correction of this error resulted in additional sequence homology between clone 208641 and agouti. However, even with the correction of this frame shift, the predicted protein sequence from this open reading frame (ORF) resulted in a protein of 94 amino acids, compared to 132 amino acids for human agouti. In addition, the predicted protein homology decreased dramatically toward the putative amino terminus. This suggested that 208641 was actually not a comlete cDNA clone, but rather an incompletely spliced hnRNA.

\section{Cloning of alternatively spliced ART transcripts}

Full-length clones corresponding to the partial sequence contained in clone 208641 were obtained from doublestranded cDNA derived from adrenal gland, subthalamic nucleus, and lung. 5' Rapid amplification of cDNA ends (RACE) analysis of cDNAs from adrenal gland or subthalamic nucleus revealed amplicons of 500 and $700 \mathrm{bp}$, respectively. Analysis of the sequence from these amplicons confirmed them as ART transcripts. Both of these inserts contained an ORF with the same coding potential, but differed in the amount of apparent $5^{\prime}$-untranslated sequence. $3^{\prime}$ RACE using RNA from all three tissues produced an amplicon of the same size $(300 \mathrm{bp})$ and predicted protein-coding sequence.

The combined sequence obtained from subthalamic nucleus RACE reactions is shown in Figure 1. As mentioned above, the sequence from the adrenal gland and lung predicted the same ORF, but differed in the length of the presumed 5'-untranslated region. This cDNA sequence contains in-frame termination codons upstream from the presumed translation start site, a termination codon, a polyadenylation signal, and a poly(A) tail. The protein predicted from this ORF contains 132 amino acids, a signal peptide sequence, and 11 cysteines.

\section{Human and mouse genomic cloning}

To investigate further the alternative splicing suggested from the cDNA clones, we isolated human genomic clones that contained the entire coding region. A $2.3-\mathrm{kb}$ EcoRI fragment was found to contain three coding exons, as well as one upstream noncoding exon (Fig. 2). This noncoding exon was identical to the presumed $5^{\prime}$-untranslated region found in subthalamic nucleus cDNA. The smaller transcripts present in the peripheral tissues seem to be attributable to the absence of this noncoding exon. Although the general genomic organization of three coding exons is preserved between ART and agouti, the intron/exon boundaries are not in identical positions (shown in Fig. 3). Given the weak homology observed outside the cysteine-rich coding regions of the genes, it is not clear whether a common ancestor gene exists.

The murine ART genomic clone was obtained as a 4-kb XbaI fragment. All splice donor and acceptor se- 


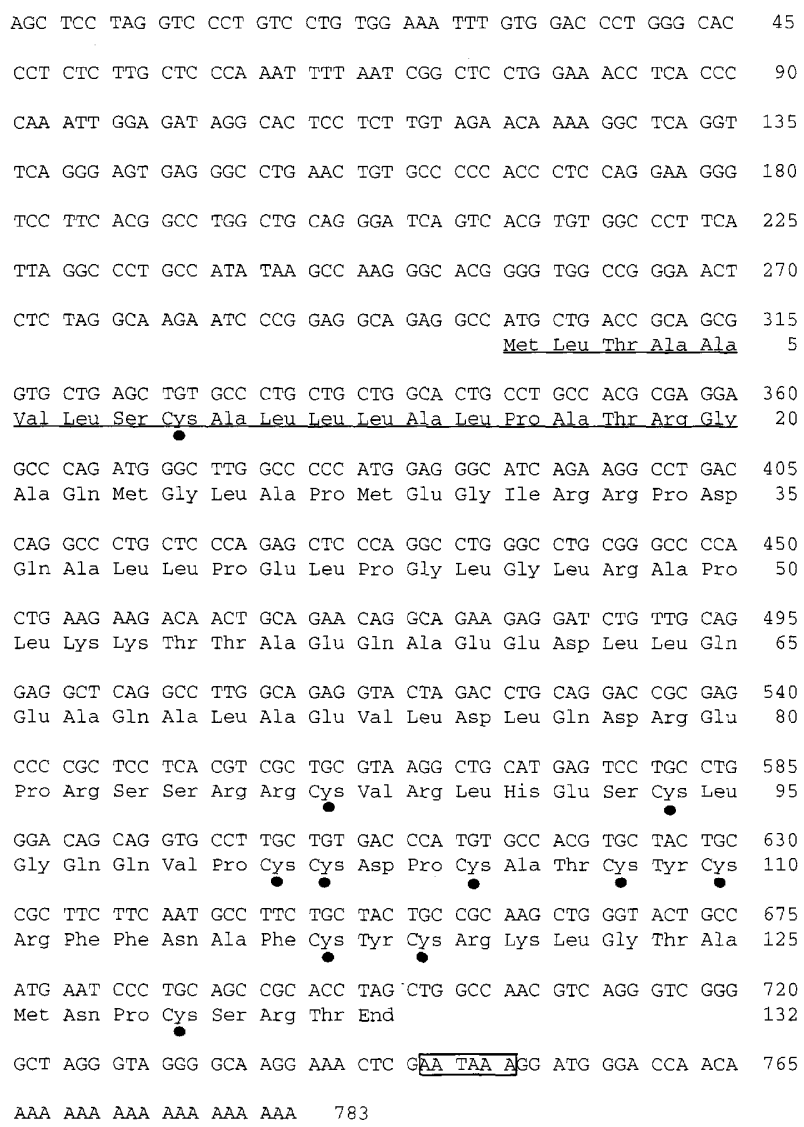

Figure 1. Human ART cDNA sequence obtained from RACE reactions using subthalamic nucleus RNA. The presumed signal sequence is underlined, the polyadenylation signal is boxed, and the location of the 11 cysteines is denoted by dots.

quences were conserved between mouse and human, allowing determination of the cDNA and predicted protein sequences. The mouse gene is predicted to encode a 131amino-acid protein that is $81 \%$ identical to the human gene (Fig. 3). Similarly, mouse agouti is also predicted to encode a polypeptide that is one amino acid shorter than the human protein.

\section{$A R T$ and agouti conserve cysteine residues}

Comparison of the peptide sequences of human agouti, human and mouse ART, and the spider toxin plectoxin VIII is shown in Figure 3. Overall, human ART is $25 \%$ identical (48\% similar) with human agouti, although the highest degree of sequence conservation is present in the carboxyl terminus of both proteins. Fifty percent of the amino acids in the carboxyl terminus (starting with cysteine-93 of agouti) are identical. The region of basic amino acids in the middle of agouti (denoted by a box) is not conserved in ART, nor is the series of polyproline residues. Mouse ART is $81 \%$ identical to human ART at the amino acid level.

Both ART and agouti have 11 cysteines, 9 of which are conserved upon alignment of the proteins. Both mature proteins are predicted to have 10 cysteines. Physical measurements of the agouti protein indicate the forma- tion of five disulfide bonds (Willard et al. 1995). In addition, eight of these cysteines are also conserved with a class of spider and snail toxins, one of which (plectoxin VIII from the primitive hunting spider Plectreurys tristis) is shown in Figure 3.

\section{Expression patterns of human and mouse $A R T$ are similar}

The expression pattern of human ART was determined by Northern blot analysis of RNA from a variety of peripheral, brain, and endocrine tissues. A striking and relatively specific pattern of expression for this novel gene (Fig. 4A) was observed in human tissues. The most abundant site of expression was the adrenal cortex, followed by the adrenal medulla, hypothalamus, subthalamic nucleus, and testis. A weak hybridization signal was detected in lung and kidney. Examination of the Northern blot with reference to the size markers revealed a transcript size of $\sim 0.7 \mathrm{~kb}$ in brain tissues, whereas peripheral tissues had a smaller transcript of $\sim 0.5 \mathrm{~kb}$. This transcript size difference is presumably the result of alternative splicing of the $5^{\prime}$ noncoding exon described above.

The expression pattern of murine ART was determined by RT-PCR analysis of RNA from a variety of tissues. Amplification of the RNA is predicted to produce a 393-bp product, whereas any contaminating genomic DNA yields a 733-bp fragment. The murine gene was found to be expressed in whole brain, hypothalamus, adrenal gland, lung, and testis, and was not detected in a number of other peripheral tissues (Fig. 4B).

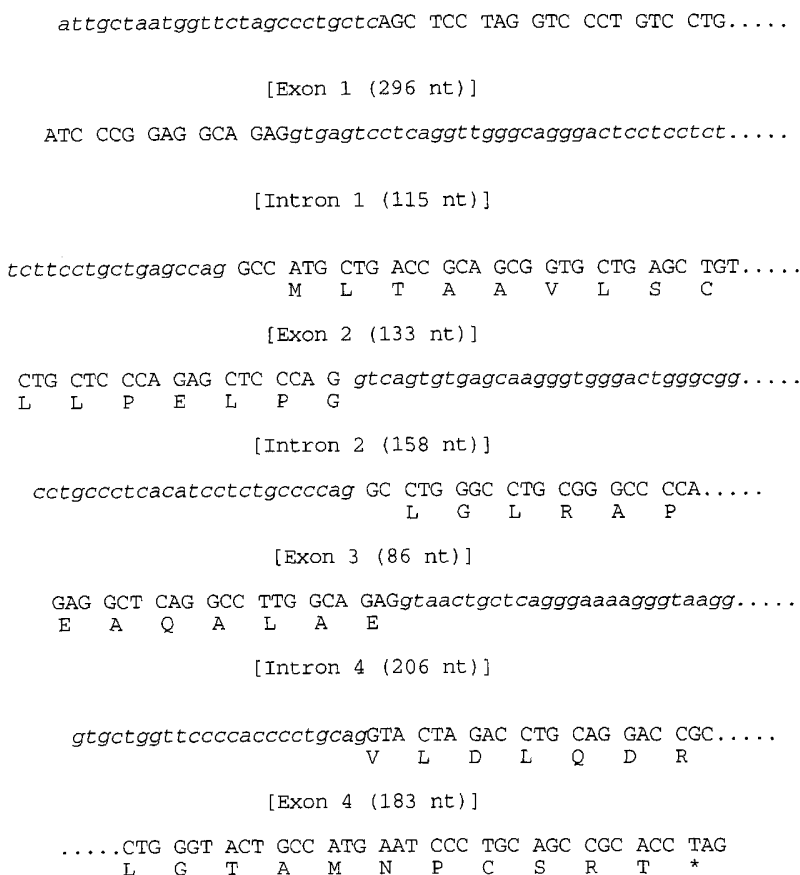

Figure 2. Sequence of the human genomic ART gene surrounding the splice-acceptor sites. The nucleotide sequence shown is uppercase letters for exons and lowercase letters for intronic DNA. 


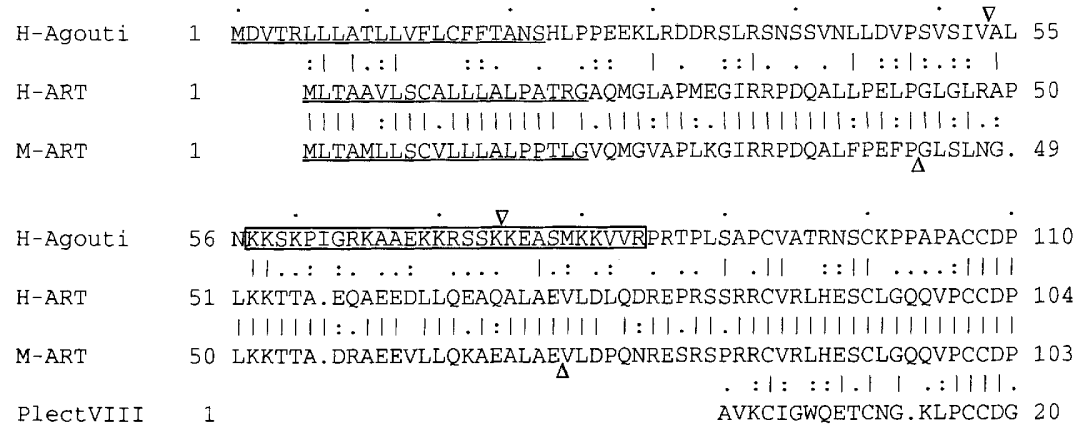

Figure 3. Comparison of the predicted amino acid sequence for human agouti, human and mouse ART, and the spider toxin plectoxin VIII. Amino acid identity is denoted by a solid line, and similarity by dots. The basic region is boxed in human agouti. The location of the three coding exons for agouti and the ART genes are shown by open arrowheads.

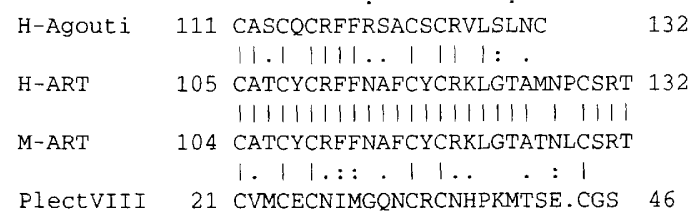

Expression of ART in mouse and rat tissues was examined in more detail by in situ hybridization. Expression of ART within the central nervous system was strikingly restricted to the arcuate nucleus and the median eminence (Fig. 5A-D). Within the median eminence, the expression appears confined to the inner palisade zone. Adjacent sections hybridized with probes to either neuropeptide Y (NPY) or pro-opiomelanocortin (POMC) revealed that the expression domain of ART in the hypothalamus resembled most closely that of NPY (Fig. 5E,F). In peripheral tissues, expression was detected in the adrenal medulla but not the cortex (Fig. 5G,H). Within the testis, a generalized low-level expression pattern was observed (data not shown).

\section{$A R T$ expression is up-regulated in mouse models of obesity}

To examine further the hypothalamic expression, we investigated the expression of ART in animal models of obesity. Sections from $o b / o b$ animals showed a markedly increased density of silver grains in the arcuate nucleus (Fig. 6B) relative to sections from non-mutant control animals (Fig. 6A). Careful comparison of the signal in the arcuate nucleus versus the median eminence shows that ART expression is not elevated in the median eminence of $o b / o b$ animals.

To confirm and quantify more closely this elevated expression, we performed RT-PCR on hypothalamic RNA isolated from normal mice (five animals, mean $=22.2 \mathrm{~g}$ ), spontaneously obese CD-1 mice (five animals, mean $=51.5 \mathrm{~g}$ ), $o b / o b$ mice (five animals, mean $=76.4 \mathrm{~g}$ ), and $d b / d b$ mice (five animals, mean $=36.9$ ). Serial 10 -fold dilutions of the RNA, starting with $10 \mathrm{ng}$, were used as the template. RNA isolated from obese $(o b)$ and diabetic $(d b)$ mutant animals showed an $\sim 10$-fold greater expression of ART relative to both normal and obese CD-1 mice (Fig. 6C). Because elevated cortisol levels are a known sequelae of obesity in $o b / o b$ and $d b / d b$ animals, we investigated whether the ART up-regulation was attributable to hypercortisolemia. Hypothalamic tissue from mice injected for 1 week with dexamethasone or saline control showed equivalent expression of ART (Fig. 6D), ruling out regulation by cortisol.

\section{Chromosomal localization}

Chromosome mapping of ART was determined by fluorescent in situ hybridization (FISH). Human and mouse metaphase chromosomes were derived from human peripheral blood lymphocytes or mouse embryonic stem (ES) cells, respectively. Preliminary analysis indicated that human ART was located on 16q; further localization was performed using two-color mapping with a probe specific for the heterochromatic region of $16 \mathrm{q}$ (Fig. 6A). Measurements of 10 labeled chromosomes indicated that ART was located $45 \%$ of the distance from the telomeric end of chromosome 16, and therefore, is mapped to $16 \mathrm{q} 22$.

A search for human syndromes that map near this locus revealed Bardet-Biedl syndrome (BBS2) at $16 \mathrm{q} 21$ (Online Mendelian Inheritance in Man, URL: http:// www3.ncbi.nlm.nih.gov/htbin-post/Omim/dispmim? 209900). This syndrome is characterized by mental retardation, obesity, retinitis pigmentosa, polydactyly, and hypogonadism. The syndrome shows nonallelic heterogeneity, and has been mapped to four loci on chromosomes $3,11,15$, or 16 (Carmi et al. 1995).

The mouse gene was localized initially to chromosome 8 , and confirmed by cohybridization with a probe specific for the centromeric region of chromosome 8 (Fig. 6B). Measurements of 10 specifically labeled chromosomes demonstrated that ART was located $77 \%$ of the distance from the heterochromatic-euchromatic bound- 


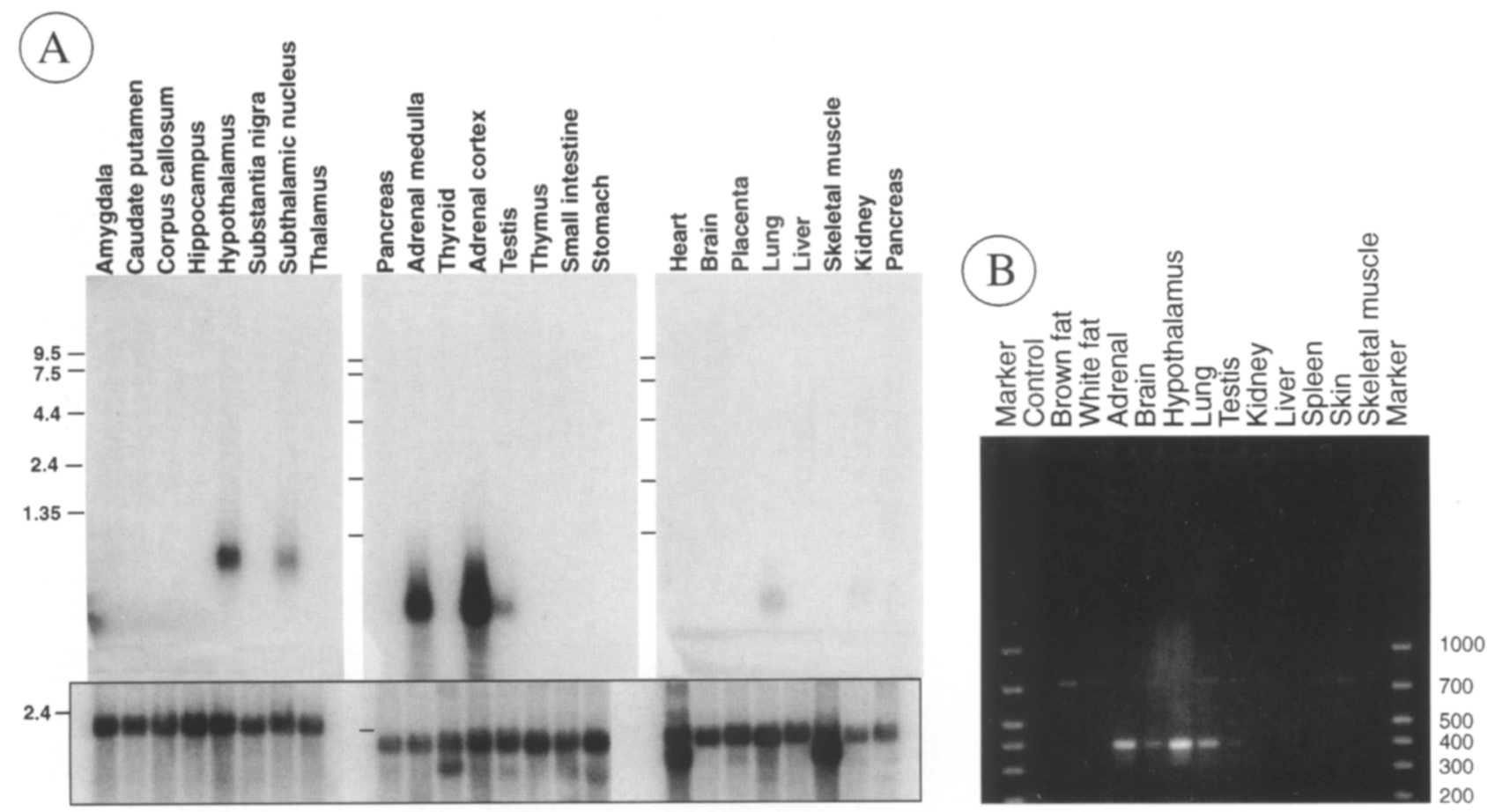

Figure 4. Expression pattern of $\operatorname{ART}$ in human $(A)$ and mouse $(B)$ tissues by Northern blot analysis or RT-PCR, respectively. $(A)$ Nylon filters containing $2 \mu \mathrm{g}$ of poly $(\mathrm{A})^{+}$RNA from a variety of human tissues were probed with a human ART cDNA probe. Note the difference in transcript size between central (brain and subthalamic nucleus) and peripheral (adrenal, testes) tissues. The filter was stripped and reprobed with $\beta$-actin to demonstrate equal loading, and to ensure accurate size determination. $(B)$ RNA from mouse tissues was amplified with ART-specific oligonucleotides, which result in a 393- or 733-bp amplicon, respectively, when RNA or genomic DNA is the template.

ary to the telomere, which corresponds to band D1-D2. This region of mouse chromosome 8 shows conservation of synteny with human chromosome 16q.

\section{Discussion}

The isolation and characterization of ART, the first gene identified with homology to agouti, establishes the presence of a new gene family. The sequence conservation with agouti implies antagonistic activity at one or more melanocortin receptors, although other actions and receptors may be involved. Although other endogenous peptide inhibitors of $G$ protein coupled receptors have been reported (Tominaga et al. 1990; Zhu and Solomon 1992), this would be the first description of a family of such genes. More broadly, the cloning of ART may provide new insights and reagents for determining the function of the melanocortin receptor family and their cognate ligands. The functional interaction between five melanocortin receptors, four ligands derived from POMC, and two endogenous peptide antagonists would provide many layers of regulation.

Agouti, a coat color gene in mice, is possibly performing other signaling functions in humans as the expression pattern is not localized to skin. This fundamental difference between mice and humans has made extrapolation and interpretation of results between these species difficult. Because the expression pattern of ART is the same between rodents and humans in all tissues examined, it is likely that both species use the protein to control the same signaling pathways. The highly specific pattern of expression, both in discrete regions of the brain and in peripheral tissues, is further indicative of a specialized role.

Within the arcuate nucleus, the expression domain of ART overlaps closely with that of NPY-, but not that of POMC-expressing neurons. Lesion and tract-tracing studies suggest that NPY-expressing neurons in the arcuate nucleus project to other hypothalamic nuclei, including a major projection to the paraventricular nucleus (Kalra and Kalra 1996). The leptin receptor is also highly expressed in this same region of the arcuate nucleus (Mercer et al. 1996). Leptin administration decreases dramatically the expression of NPY in the arcuate nucleus (Schwartz et al. 1996), and leptin-deficient (ob/ob) animals have increased expression of NPY, establishing a link between these key regulatory proteins. In contrast, POMC-expressing neurons in the arcuate nucleus project to many sites other than the paraventricular nucleus (Cheung and Hammer 1995). Therefore, the ART-expressing neurons in the arcuate nucleus are found in the same region as neurons that project to the paraventricular nucleus and influence feeding.

The elevated expression of ART in the hypothalamus 
Figure 5. Expression analysis of ART in mouse tissues using in situ hybridization. (AF) Mouse brain (coronal section) shown under bright field or dark-field illumination. (AN) arcuate nucleus; (ME) median eminence; (V3) the third ventricle. Sections were hybridized with an antisense probe for ART $(A-D)$, NPY $(E)$, or POMC $(F) .(G, H)$ Sections of mouse adrenal gland, including both the cortex and medulla, hybridized with an ART antisense probe. Original magnification $(A, B), 1 \times ;(C-H)$, $20 \times$; bar, $100 \mu \mathrm{m}$.
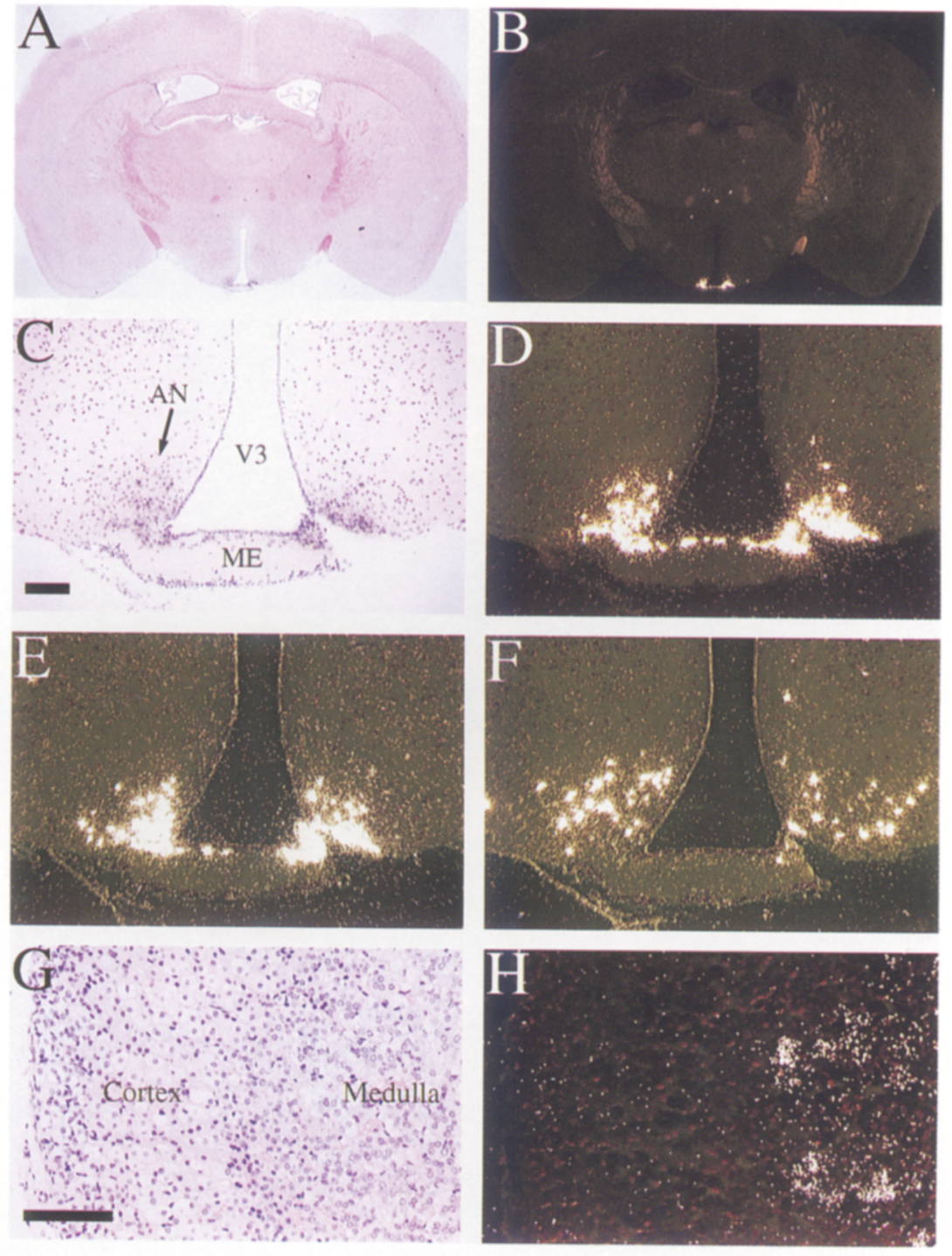

of obese and diabetic mutant mice also supports a role in the regulation of feeding. This up-regulation was observed only in neurons known to influence feeding, namely those of the arcuate nucleus. Neurons in the adjacent median eminence, which are functionally and anatomically distinct from the arcuate nucleus, did not exhibit this increased transcription. The lack of induction by dexamethasone demonstrates that this up-regulation is not attributable to hypercortisolemia secondary to obesity. Rather, the elevated expression in $o b / o b$ and $d b / d b$ animals, but not in obese, nonmutant animals, suggests that impaired leptin signaling pathways are directly involved. Elimination of NPY in $o b / o b$ animals does not reverse completely the obese phenotype leading to the suggestion that other neuromodulators may be involved in the hypothalamic response to leptin (Erickson et al. 1996). The data presented here suggest that ART may play a role in leptin signaling, and emphasize the importance of excluding ART as a candidate gene for the human syndrome BBS2.
The obese phenotype observed in mice lacking the MC4-R (Huszar et al. 1997) indicates an inhibitory role for this receptor in weight regulation. This is further supported by the ability of agonists and antagonists of MC3-R and MC4-R (Fan et al. 1997) to decrease and increase weight, respectively. Thus, the molecular basis for the obesity observed in agouti-overexpressing mice may well be antagonism at MC4-R and possibly MC3-R, and subsequent relaxation of this tonic inhibition. The data presented above, combined with these reports, suggest a model by which leptin activity may be mediated by down-regulation of $\mathrm{ART}$ transcription, leading to increased tonic inhibition of the MC3-R and/or MC4-R pathway.

It will be of great interest to determine which receptors are mediating the action of ART. Detailed localization studies in the brain have shown that MC3-R is expressed primarily in the hypothalamus and thalamus (Roselli-Rehfuss et al. 1993), whereas MC4-R is expressed in a number of other brain nuclei (Mountjoy et 

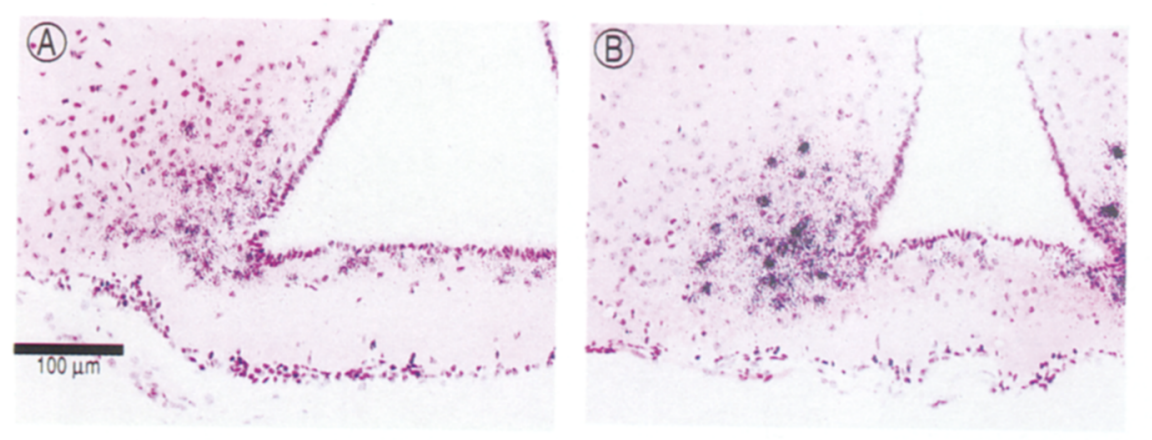

(C)
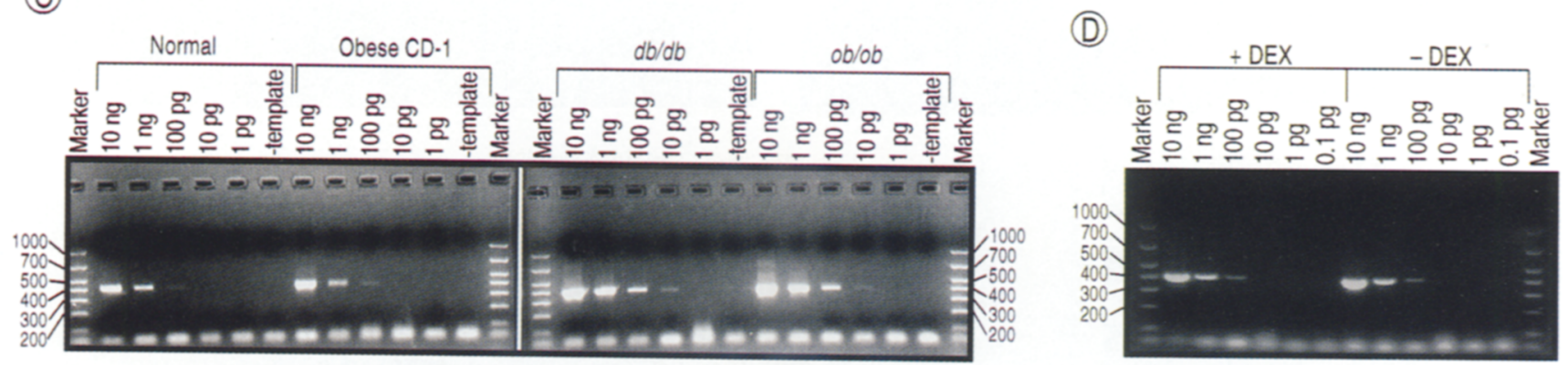

Figure 6. ART expression in animal models of obesity. Coronal sections of brains through the hypothalamus from $o b / o b$ mice $(B)$ or nonmutant mice $(A)$ hybridized and exposed under identical conditions. (C) RT-PCR analysis of ART gene expression in $o b / o b, d b / d b$, spontaneously obese CD-1, or control mice. $(D)$ RT-PCR analysis of ART gene expression in mice injected for 1 week with either dexamethasone or saline control.

al. 1994). Therefore, on the basis only of distribution patterns, it would seem that MC3-R is the more likely receptor in the brain. The arcuate nucleus is also a prominent site of POMC expression. Although the POMC gene product can be cleaved preferentially into amino-terminal (e.g., $\gamma$-MSH, $\alpha$-MSH) or carboxy-terminal ligands (e.g., $\beta$-endorphin), the neuron still releases all peptides simultaneously (Smith and Funder 1988). Perhaps the presence of a regulatory peptide specific for melanocortin receptors in the synaptic cleft allows additional attenuation of MSH and ACTH signaling, and preferential activation of the opioid pathway.

In addition to the control of feeding, the hypothalamus is also important in the regulation of the pituitary and the entire hypothalamic-pituitary axis. In particular, the arcuate nucleus projects to parvocellular neurons within the paraventricular nucleus, which regulate pituitary function by secretion of peptide factors (e.g., corticotropin-releasing hormone) into the portal vasculature. These neurons are thought to secrete these peptides in a pulsatile manner. The inner palisade zone of the median eminence contains the unmyelinated axons of the neurosecretory neurons projecting from the hypothalamus to the posterior pituitary. It is intriguing to speculate that ART may be providing temporal regulation of hypothalamic function, analagous to the haircycle-specific regulation of melanogenesis by agouti.

The expression of ART in the adrenal medulla does not appear to colocalize with any known melanocortin receptor, as both MC2-R and MC5-R are apparently confined to the cortex of the adrenal gland (Cone et al. 1996). The adrenal medulla, as opposed to the cortex, is neural crest in origin, and secretes peptides such as adrenalin and noradrenalin. Whether ART is involved in regulating the secretory function of the adrenal gland awaits further studies, as does the functional significance, if any, of the smaller splice variant of ART present in this tissue.

However, because it is still unclear whether antagonism at melanocortin receptors accounts completely for all the actions of agouti, other pathways may be involved in ART signaling. In particular, the carboxy-terminal conservation of cysteines between ART, agouti, and spider toxins may suggest a role for other pathways, possibly by regulating intracellular calcium levels. These cysteines have been predicted from three-dimensional nuclear magnetic resonance studies to form four disulfide bridges that constrain the toxin into a biologically active structure (Kim et al. 1995).

The known biological activities of agouti, the hypothalamic localization of melanocortin receptors, and the phenotype of mice lacking MC4-R has implicated these gene products in the control of obesity. The sequence homology of ART to agouti and its expression pattern suggests a role in the regulation of melanocortin receptors in the hypothalamus and adrenal gland. The elevated expression of ART in mutant animal models of obesity identifies a potential participant in the hypothalamic control of feeding. 

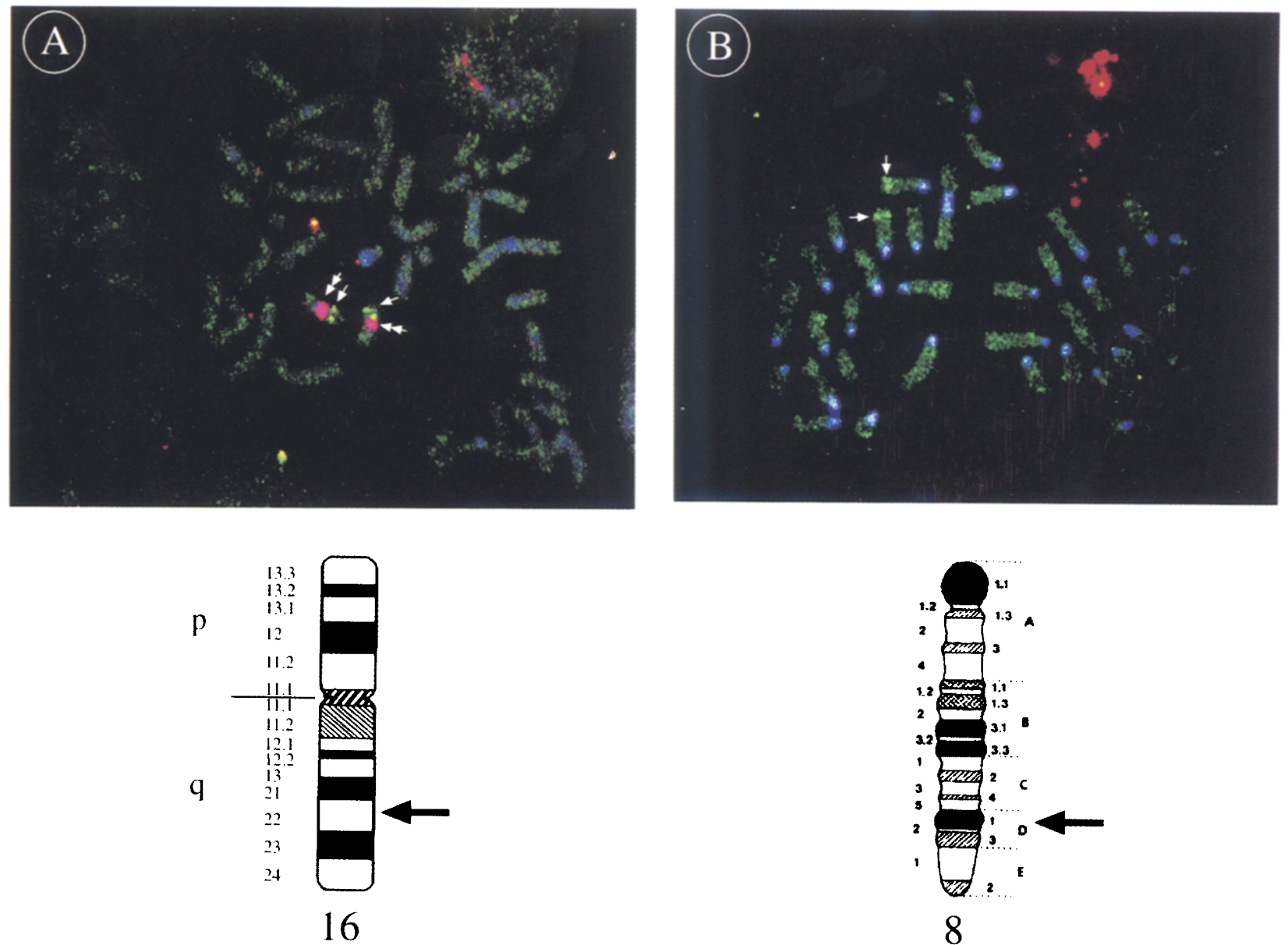

Figure 7. FISH mapping of human $(A)$ or mouse $(B)$ gene to chromosomes from peripheral blood leukocytes or male ES cells, respectively. (A) A biotin-labeled probe specific for the heterochromatic region of chromosome 16 is indicated by double arrowheads, whereas a digoxigenin-labeled P1 clone containing human ART is denoted by single arrowheads. This corresponds to human chromosome 16q22 (bottom). (B) Specific labeling of chromosome 8 by a digoxigenin-labeled BAC clone containing mouse ART sequences is indicated by single arrowhead. This region corresponds to mouse chromosome 8D1-D2 (bottom).

\section{Materials and methods \\ GenBank EST search}

The public EST database was searched with a sequence profile (Gribskov et al. 1987; Lüthy et al. 1994) constructed from the human and murine agouti peptide sequence. One submission (H63735) was found to have homology to this profile. The submission containing the sequence from the opposite end of this cDNA clone was obtained (H63298), but did not show any homology to the profile. The bacterial stock containing the cDNA clone (I.M.A.G.E. Consortium CloneID 208641) corresponding to these two submissions was obtained (Genome Systems, St. Louis, MO). DNA isolated from this clone (Qiagen) was sequenced both to confirm the identity of the clone as well as to extend the sequence.

\section{Northern blot analysis}

Nylon filters containing immobilized human poly(A) RNA ( $2 \mu \mathrm{g}$ per lane) from a variety of human tissues (Clontech) were examined for ART expression. Clone 208641 was digested with NcoI-NotI to generate a 600 -bp probe, which was then labeled radioactively with $\left[\alpha^{-32} \mathrm{P}\right] \mathrm{dCTP}$ (RediVue, Amersham) in a random-primed reaction (RediPrime, Amersham). Unincorporated radioactivity was excluded by size exclusion chromatography (QuickSpin columns, Boehringer Mannheim). The filters were hybridized overnight at $42^{\circ} \mathrm{C}$ in buffer containing $50 \%$ formamide, $2 \%$ SDS, $10 \times$ Denhardt's, $100 \mu \mathrm{g} / \mathrm{ml}$ of salmon sperm DNA, and $5 \times$ SSPE. The filters were then washed in $2 \times$ SSC, $0.05 \%$ SDS at room temperature for $40 \mathrm{~min}$ with three changes of wash solution, followed by $30 \mathrm{~min}$ at $50^{\circ} \mathrm{C}$ in $0.1 \times \mathrm{SSC}, 0.1 \%$ SDS. Hybridization signals were detected by placing the filters in a PhosphorImager cassette (Molecular Dynamics) overnight.

\section{RACE cloning}

To obtain the full-length cDNA clone corresponding to clone 208641, human poly(A) ${ }^{+}$RNA (Clontech) from adrenal gland, subthalamic nucleus, and lung was reverse transcribed, second strand cDNA was synthesized, and ligated to adapter primers using the Marathon cDNA amplification kit /Clontech). The final cDNA products were purified from unligated adapter primers (PCR Clean-up kit, Qiagen), and used as a template for subsequent RACE reactions using PCR. PCR was per- 
formed with the AP1 primer $15^{\prime}$-CCATCCTAATACGACTCACTATAGGGC-3') and a gene-specific primer using the Advantage PCR kit components (Clontech). For the $5^{\prime} \mathrm{RACE}$, the gene-specific primer was 1275-34 (5'-TAGCCCCGACCCTGACGTTGGC-3'); for the 3' RACE, the primer number 1291$71\left(5^{\prime}\right.$-GCTCCTCACGTCGCTGCGTAA-3') was used. After an initial denaturation step $\left(94^{\circ} \mathrm{C}, 3 \mathrm{~min}\right)$, the reactions were cycled five times at $94^{\circ} \mathrm{C}, 15 \mathrm{sec}, 72^{\circ} \mathrm{C}, 2 \mathrm{~min}$; five times at $94^{\circ} \mathrm{C}, 15 \mathrm{sec}, 70^{\circ} \mathrm{C}, 2 \mathrm{~min}$; and 25 cycles at $94^{\circ} \mathrm{C}, 15 \mathrm{sec}, 68^{\circ} \mathrm{C}$, 2 min on a Perkin Elmer 2400 PCR machine.

For 5' RACE, an aliquot of the reaction mix was electrophoresed on an agarose gel, and the bands migrating at $\sim 600 \mathrm{bp}$ were excised and purified (Gel Extraction kit, Qiagen) and used as a template for subsequent PCR using the nested primer AP2 (5'ACTCACTATAGGGCTCGAGCGGC-3') and oligonucleotide 1275-34. The PCR conditions were the same as previously described.

To subclone the PCR products from the nested $5^{\prime}$ RACE and the $3^{\prime}$ RACE reactions, an aliquot was electrophoresed on agarose, and the desired bands were excised, purified, and cloned into a plasmid (TA Cloning kit, Invitrogen). DNA was purified from bacteria containing the plasmid (Qiagen), digested with EcoRI and electrophoresed to confirm the presence and size of the insert. Clones containing a variety of insert sizes were sequenced with $\mathrm{T} 7$ and M13 primers. The sequence obtained was used to determine which clones had inserts that contained ART cDNA, and to design oligonucleotide primers to the $5^{\prime}$ portion of the cDNA.

\section{Genomic cloning}

High-density filters spotted with DNA from human genomic P1 clones (Genome Systems) were hybridized with $\left[\alpha{ }^{32} \mathrm{P}\right] \mathrm{dCTP}-$ labeled NcoI-NotI probe described above in RapidHyb buffer (Amersham) at $65^{\circ} \mathrm{C}$ for $4 \mathrm{hr}$. The filters were then washed in $2 \times \mathrm{SSC}, 0.2 \% \mathrm{SDS}$ at room temperature for $30 \mathrm{~min}$, and then in $0.2 \times \mathrm{SSC}, 0.2 \%$ SDS at $65^{\circ} \mathrm{C}$ for $30 \mathrm{~min}$. The filters were placed into autoradiograph cassettes with Hyperfilm (Amersham) and placed at $-80^{\circ} \mathrm{C}$ overnight. The film was then developed, and the coordinates of $\mathrm{P} 1$ clones that hybridized to the probe were recorded. Bacterial stocks containing these positive $\mathrm{Pl}$ clones were obtained (Genome Systems) and DNA isolated (Qiagen).

To obtain the mouse genomic clones a phage library (Stratagene) and high-density filters spotted with a mouse bacterial artificial chromosome (BAC) library (Genome Systems) were screened with the full-length human ART cDNA or a 220-bp probe from the cysteine-rich region generated by PCR using oligonucleotides $1297-71$ and 1275-34, respectively.

An aliquot of DNA was digested with EcoRI, electrophoresed on a $0.9 \%$ agarose gel, and the bands migrating at $\sim 2-3 \mathrm{~kb}$ excised, purified, and subcloned (Bluescript KSII, Stratagene). DNA was isolated from bacteria-containing inserts (Qiagen), digested with EcoRI, electrophoresed, transferred to nylon filters (Turboblotter, S\&S), and UV cross-linked (Stratagene). These filters were then hybridized with the NcoI-NotI probe (human P1 clones) or the 220-bp probe (mouse BAC clones) as described above to identify clones that contained ART sequences. DNA from these clones was then sequenced to provide the genomic structure of the gene.

\section{$R T-P C R$}

RNA was prepared from the tissues indicated using the RNeasyTotal RNA Kit (Qiagen). Oligonucleotides flanking the coding region of murine ART were used to amplify total RNA using the GeneAmp EZ rTth RNA PCR Kit (Perkin Elmer) for 35 cycles.
Twenty-five percent of the reaction was run on a $1.25 \%$ agarose gel for visualization. The amplicon from RNA is $393 \mathrm{bp}$, whereas any contaminating genomic DNA yields a 733-bp fragment.

\section{FISH mapping}

DNA was isolated from either a P1 clone or mouse BAC clone containing human or mouse genomic ART sequences, respectively. The DNA was labeled with digoxigenin dUTP by nick translation. Labeled probe was combined with sheared human or mouse DNA and hybridized to normal metaphase chromosomes derived from phytohemagglutinin (PHA)-stimulated peripheral blood lymphocytes or mouse ES cells in a solution containing $50 \%$ formamide, $10 \%$ dextran sulfate, and $2 \times$ SSC. Specific hybridization signals were detected by incubating the hybridized slides in fluoresceinated anti-digoxigenin antibodies followed by counterstaining with propidium iodide for onecolor experiments. Signal detection for two-color experiments was the same except for the inclusion of avidin Texas red and counterstaining with DAPI. For the human gene, a biotin-labeled probe specific for the heterochromatic region of chromosome 16 was cohybridized with the $\mathrm{Pl}$ probe, resulting in the heterochromatic region visualized in red, and the long arm of chromosome 16 in green. Measurement of 10 specifically hybridized chromosomes 16 were used to determine the distance from the telomere to the $\mathrm{P} 1$ probe location.

\section{In situ hybridization}

Tissues were rapidly dissected, fixed overnight in $4 \%$ paraformaldehyde, embedded in paraffin, and sectioned at $5 \mu \mathrm{m}$. A probe encompassing the full-length coding sequence of mouse ART was cloned into PCR2.1 (Invitrogen). UTP labeled with ${ }^{32} \mathrm{P}$ (Amersham) was used to synthesize an antisense riboprobe from the linearized plasmid template, and in situ hybridization was performed as described (Ellison et al. 1996).

\section{Acknowledgments}

We gratefully acknowledge Laarni Antonio for DNA sequencing, Bob Bosselman, Eileen Curran, and Andrew Welcher for helpful discussions, Mary Ann Pelleymounter for tissue samples, and the support of the Amgen Genome Project.

The publication costs of this article were defrayed in part by payment of page charges. This article must therefore be hereby marked "advertisement" in accordance with 18 USC section 1734 solely to indicate this fact.

\section{Note added in proof}

The sequence data described in this paper have been submitted to GenBank under accession number U-88063.

\section{References}

Bultman, S.J., E.J. Michaud, and R.P. Woychik. 1992. Molecular characterization of the mouse agouti locus. Cell 71: 11951204.

Carmi, R., K. Elbedour, E.M. Stone, and V.C. Sheffield. 1995. Phenotypic differences among patients with Bardet-Biedl syndrome linked to three different chromosome loci. Am. J. Med. Genet. 59: 100-203.

Cheung, S. and R.P. Hammer. 1995. Gonadal-steroid hormone regulation of proopiomelanocortin gene-expression in arcu- 
ate neurons that innervate the medial preoptic area of the rat. Neuroendocrinology 62: 283-292.

Cone, R.G., D. Lu, S. Koppula, D. Vage, H. Klungsland, B. Boston, W. Chen, D.N. Orth, C. Pouton, and R.A. Kesterson. 1996. The melanocortin receptors: Agonists, antagonists, and the hormonal control of pigmentation. Recent Prog. Horm. Res. 51: 287-318.

Ellison, J.A., S. Scully, and J. deVellis. 1996. Evidence for neuronal regulation of oligodendrocyte development: Cellular localization of platelet-derived growth factor $\alpha$ receptor and $\alpha$-chain mRNA during cerebral cortex development in the rat. I. Neurosci. Res. 45: 28-39.

Erickson, J.C., G. Hollopeter, and R.D. Palmiter. 1996. Attenuation of the obesity syndrome of ob/ob mice by the loss of neuropeptide Y. Science 274: 1704-1707.

Fan, W., B.A. Boston, R.A. Kesterson, V.J. Hruby, and R.D. Cone. 1997. Role of melanocortinergic neurons in feeding and the agouti obesity syndrome. Nature 385: 165-168.

Figueiredo, S.G., M. Garcia, A. Valentim, M. Cordeiro, C. Diniz, and M. Richardson. 1995. Purification and amino acid sequence of the insecticidal neurotoxin $T \times 4(6-1)$ from the venom of the "armed" spider Phoneutria nigriventer (keys). Toxicon 33: 83-93.

Gribskov, M., A.D. McLachlan, and D. Eisenberg. 1987. Profile analysis: Detection of distantly related proteins. Proc. Natl. Acad. Sci. 13: 4355-4358.

Huszar, D., C.A. Lynch, V. Fairchild-Huntress, J.H. Dunmore, Q. Fand, L.R. Berkemeier, B.A. Boston, R.D. Cone, F.J. Smith, L.A. Campfield, P. Burn, and F. Lee. 1997. Targeted disruption of the melanocortin-4 receptor results in obesity in mice. Cell 88: 131-141.

Ichida, S., T. Wada, M. Sekiguchi, H. Kishino, Y. Okazaki, and T. Akimoto. 1993. Characteristics of specific 125I-omegaconotoxin GVIA binding in rat whole brain. Neurochem. Res. 18: 1137-1144.

Jackson, I.J. 1993. Colour-coded switches. Nature 362: $587-$ 588.

Kalra, S.P. and P.S. Kalra. 1996. Nutritional infertility--The role of the interconnected hypothalamic neuropeptide Y-galaninopioid network. Front. Neuroendocrinol. 17: 371-401.

Kim, I., S. Konishi, H. Iwai, T. Kohno, H. Gouda, I. Shimada, K. Sato, and Y. Arata. 1995. Three-dimensional solution structure of the calcium channel antagonist $w$-agatoxin IVA: Consensus molecular folding of calcium channel blockers. $I$. Mol. Biol. 250: 659-671.

Kwon, H.J., S.J. Bultman, C. Loffler, W. Chen, P.J. Furdon, J.G. Powell, A. Usala, W. Wilkison, I. Hansmann, and R.P. Woychik. 1994. Molecular-structure and chromosomal mapping of the human homolog of the agouti gene. Proc. Natl. Acad. Sci. 91: 9760-9764.

Labbe, F., F. Desanaud, D. Eggerickx, G. Vassart, and M. Parmentier. 1994. Molecular cloning of a mouse melanocortin 5 receptor gene widely expressed in peripheral tissues. Biochemistry 33: 4543-4549.

Lu, D., D. Willard, I.R. Patel, S. Kadwell, L. Overton, T. Kost, M. Luther, W. Chen, R.P. Woychik, W.O. Wilkinson, and R.D. Cone. 1994. Agouti protein is an antagonist of the melanocyte-stimulating hormone receptor. Nature 371: 799-802.

Lüthy, R., I. Xenarios, and P. Bucher. 1994. Improving the sensitivity of the sequence profile method. Protein Sci. 3: 139-146.

Manne, J., A.C. Argeson, and L.D. Siracusa. 1995. Mechanism for the pleiotrophic effects of the agouti gene. Proc. Natl. Acad. Sci. 92: 4721-4724.

Mercer, J.G., N. Hoggard, L.M. Williams, C.B. Lawrence, L.T. Hannah, P.J. Morgan, and P. Trayhurn. 1996. Coexpression of leptin receptor and preproneuropeptide Y messenger RNA in arcuate nucleus of mouse hypothalamus. J. Neuroendocrinol. 8: 733-735.

Mountjoy, K.P., L.S. Robbins, M.T. Mortrud, and R.D. Cone. 1992. The cloning of a family of genes that encode the melanocortin receptors. Science 257: 1248-1251.

Mountjoy, K.G., M.T. Mortrud, M.J. Low, R.B. Simerly, and R.D. Cone. 1994. Localization of the melanocortin-4 receptor (MC4-R) in neuroendocrine and autonomic control circuits in the brain. Mol. Endocrinol. 8: 1298-1308.

Roselli-Rehfuss, L., K.G. Mountjoy, L.S. Robbins, M.T. Mortrud, M.J. Low, J.B. Tatro, M.L. Entwistle, R.B. Simerly, and R.D. Cone. 1993. Identification of a receptor for gamma melanotropin and other proopiomelanocortin peptides in the hypothalamus and limbic system. Proc. Nat1. Acad. Sci. 90: 8856-8860.

Schwartz, M.W., R.J. Seeley, L.A. Campfield, P. Burn, and D.G. Baskin. 1996. Identification of targets of leptin action in rat hypothalamus. I. Clin. Invest. 98: 1101-1106.

Searle, A.G. 1968. Comparative genetics of coat colour in mammals. Academic Press, New York, NY.

Smith, A.I. and J.W. Funder. 1988. Proopiomelanocortin processing in the pituitary, central nervous system, and peripheral tissues. Endocrinol. Rev. 9: 159-179.

Takeuchi, T., T. Kobunai, and H. Yamamoto. 1989. Genetic control of signal transduction in mouse melanocytes. $J$. Invest. Dermatol. 92: 239S-242S.

Tominaga, T., J. Fukata, Y. Naito, S. Funakosko, N. Fujii, and H. Imura. 1990. Effects of corticostatin-I on rat adrenal cells in vitro. I. Endocrinol. 125: 287-292.

Willard, D.H., W. Bodnar, C. Harris, L. Kiefer, J.S. Nichols, S. Blanchard, C. Hoffman, M. Moyer, W. Burkhart, and J. Weiel, et al. 1995. Agouti structure and function: Characterization of a potent alpha-melanocyte stimulating hormone receptor antagonist. Biochemistry 34: 12341-12346.

Wilson, B.D., M.M. Ollmann, L. Kang, M. Stoffel, G.I. Bell, and G.S. Barsh. 1995. Structure and function of ASP, the human homolog of the mouse agouti gene. Hum. Mol. Genet. 4: $233-230$.

Zemel, M.B., J.H. Kim, R.P. Woychik, E.J. Michaud, S.H. Kadwell, I.R. Patel, and W.O. Wilkinson. 1995. Agouti regulation of intracellular calcium-role in the insulin resistance of viable-yellow mice. Proc. Nat1. Acad. Sci. 92: 4728-4732.

Zhu, Q. and S. Solomon. 1992. Isolation and mode of action of rabbit corticostatic (antiadrenocorticotropin) peptides. Endocrinology 130: 1413-1423. 


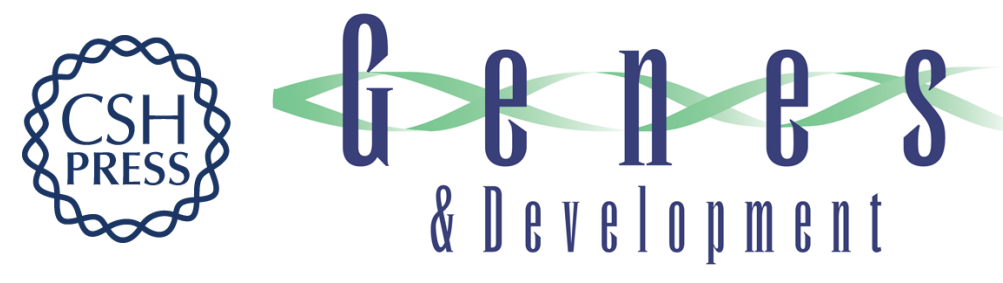

\section{Hypothalamic expression of ART, a novel gene related to agouti, is up-regulated in obese and diabetic mutant mice.}

J R Shutter, M Graham, A C Kinsey, et al.

Genes Dev. 1997, 11:

Access the most recent version at doi:10.1101/gad.11.5.593

References This article cites 31 articles, 7 of which can be accessed free at: http://genesdev.cshlp.org/content/11/5/593.full.html\#ref-list-1

License

Email Alerting

Receive free email alerts when new articles cite this article - sign up in the box at the top Service right corner of the article or click here.

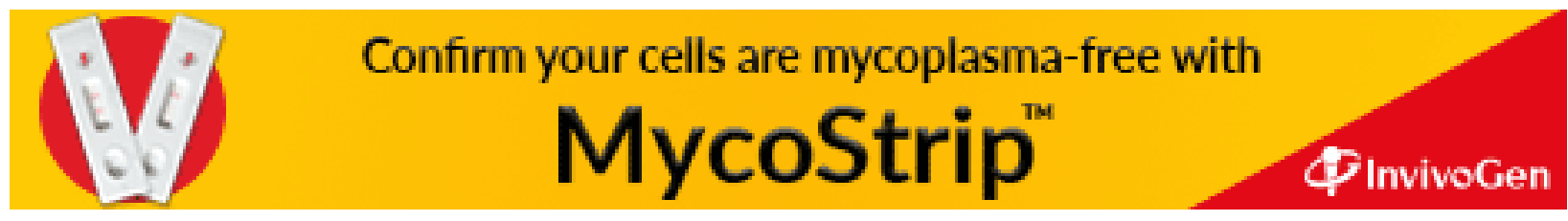

